\title{
Article \\ Spillage-Adaptive Fixed-Geometry Bump Inlet of Wide Speed Range
}

\author{
Zonghan $\mathrm{Yu}$ *, Guoping Huang, Ruilin Wang and Omer Musa *
}

check for updates

Citation: Yu, Z.; Huang, G.; Wang,

R.; Musa, O. Spillage-Adaptive

Fixed-Geometry Bump Inlet of Wide Speed Range. Aerospace 2021, 8, 340. https://doi.org/10.3390/aerospace 8110340

Academic Editors: Sergey Leonov and Kojiro Suzuki

Received: 25 September 2021

Accepted: 2 November 2021

Published: 11 November 2021

Publisher's Note: MDPI stays neutral with regard to jurisdictional claims in published maps and institutional affiliations.

Copyright: (c) 2021 by the authors. Licensee MDPI, Basel, Switzerland. This article is an open access article distributed under the terms and conditions of the Creative Commons Attribution (CC BY) license (https:/ / creativecommons.org/licenses/by/ $4.0 /)$.
College of Energy and Power Engineering, Nanjing University of Aeronautics and Astronautics, Nanjing 210016, China; hgp@nuaa.edu.cn (G.H.); wangruilin@nuaa.edu.cn (R.W.)

* Correspondence: yzh@nuaa.edu.cn (Z.Y.); omermusa@nuaa.edu.cn (O.M.)
Abstract: In this work, a new spillage-adaptive bump inlet concept is proposed to widen the speed range for hypersonic air-breathing flight vehicles. Various approaches to improve the inlet startability are summarized and compared, among which the bump-inlet pattern holds the merits of high lift-to-drag ratio, boundary layer diversion, and flexible integration ability. The proposed spillage-adaptive concept ensures the inlet starting performance by spilling extra mass flow away at low speed number conditions. The inlet presetting position is determined by synthetically evaluating the flow uniformity and the low-kinetic-energy fluid proportion. The numerical results show that the flow spillage of the inlet increases with the inflow speed decrease, which makes the inlet easier to start at low speed conditions (M 2.5-6.0). The effects of the boundary layer on spillage are also studied in this work. The new integration pattern releases the flow spillage potentials of three-dimensional inward-turning inlets by reasonably arranging the inlet compression on the bump surface. Future work will focus on the spillage-controllable design method.

Keywords: wide speed range; air-breathing flight vehicle; flow spillage; inlet-airframe integration; inlet start

\section{Introduction}

Hypersonic inlet design is crucial to achieving the target of rapid global arrival [1-4]. The contribution of inlets to the propulsion system is estimated [5] as follows: According to the maximum temperature limit which the material can bear at present (the temperature limit is approximately $2000 \mathrm{~K}$ ), the converted energy by inlet compression occupies $12 \%$ of the added energy by combustion at M 1.8, while it increases to $66.7 \%$ at M 3.4. This energy reaches approximately $230 \%$ at M 4.5 . The trend reveals that a tiny increase of the energy loss in the inlets will induce considerable deterioration in the whole characteristics of the propulsion system at high-speed conditions [6-8].

The inlet start is the essential requirement to ensure its efficient working at off-design conditions. Abundant studies have been conducted to clarify the unstart mechanism and widen the inlet speed range. The direct cause of inlet unstart is that the swallowed inflow exceeds the flow capacity of the throat. Except for the backpressure fluctuation from the combustor [9-11], the internal contraction ratio (ICR) is the key parameter to determine the inlet start. Kantrowitz [12] first proposed the inviscid ICR calculating equation based on 1D steady flow assumption. The corresponding ICR limit is obtained when the ending shock is located at the entrance, and $M_{\text {throat }}$ approaches 1.0. Xie [13,14] developed a threelayer model to predict the ICR limit at viscous conditions. The improvement of inlet start performance is carried out in two directions: one is to decrease the internal compression ratio and the other is to remove the boundary layer. Wang [15] developed an image detection method to quantitively analyze the correlation between shock oscillation and the dynamic wall pressure in hypersonic experiments. Yu [16] proposed a high external compression ratio basic flow field. The speed range is widened by approximately $3.5 \%$ in $\mathrm{M}$ 3.5 through decreasing the external/internal contraction ratio by $38 \%$. Xiong [17] developed 
a new method to design the basic flow field, which can optimize the compression efficiency without meshing. The new basic flow field's total pressure recovery $(\sigma)$ increases by $7.65 \%$ than the original one. The $\sigma$ of the newly designed inlet increases by $5.65 \%$. Chen and Ding $[18,19]$ proposed the external-internal basic flow field integration method based on the method of characteristics and the streamline tracing technique. This mechanism leads to more flexibility to reasonably arrange the external/internal flow. Similar methodologies are also developed by Qiao [20,21], and the starting speed range for M 7.0 inlet is widened to 4.5 (the self-starting Mach number is approximately 5.2). Zhou and Jin [22,23] developed a non-axisymmetric generalized internal conical basic flow field, which increases the design flexibility for the arbitrary inlet shapes and non-uniform inflow.

The improvement of the basic flow field is to widen the inlet speed range. Nevertheless, the swallowed boundary layer accumulates at the low-pressure region in the inlet, which will restrict the flow capacity and cause the interaction between boundary layer and shock $[24,25]$. Hence, the boundary layer treatments are essential to enlarge the effective flow area. The boundary layer bleed is one of the standard techniques [26]. The bleeding control uses the pressure gap to divert the boundary layer away. The German Aerospace Center [27] (DLR) conducted a M 6 wind tunnel test of a fixed geometry scramjet inlet. The inlet started by integrating the boundary layer bleed at the throat. The influence of backpressure to the internal flow structure was obtained. Goldfeld [28] conducted $\mathrm{M}$ 3-7 experiments of a hypersonic inlet. The effects of two different bleed angles to the bleed coefficient are studied. Liu and Fan [29] studied the unstart mechanism under two modes: the backpressure and the bleed holes. A two-separation-region mechanism to describe inlet local unstart is established by comparing the experimental results of the start/unstart at M 7. The von Karman Institute for Fluid Dynamics [30] proposed a bypass bleed system for ramjet, which connects the compression part and the expansion ramps. This system will simultaneously divert the upstream boundary layer and eliminate the downstream separation bubble, promisingly reducing the mechanism complexity. As presented above, the bleeding control can efficiently remove the boundary layer, while the burden of structural strength increases with the bleed area; hence, its application in the flow field with thick LKE fluid is relatively inefficient. The bump technique is preferable while synthetically considering boundary layer diversion and the mechanism complexity. The lateral pressure gradient is the key to divert the near-wall LKE fluid. The classical bump surface is generated by streamline tracing method in the conical flow field [31]. The pressure controllable bump is proposed by Qiao and Huang [32,33] to avoid overlarge height while keeping identical boundary layer removal. The pressure ridge (PR) mechanism [34] is established to arrange the bump pressure. Accordingly, the speed range extends from supersonic to hypersonic speed. Meanwhile, the inlet start performance is still restricted (M 5.0). The overlarge compression caused by the expanded compressed flow pattern is the main reason, which will be analyzed in detail in Section 2.1.

This work proposes a new side-located bump inlet integration pattern to enlarge the inlet start-ability. A modular assessment approach is used to qualitatively analyze the merits of side compression pattern. Successively, the design methodology of novel spillage adaptive concept is presented to generate the side-located bump inlet integration form. The numerical methods are validated by experiments to prove its accuracy on flow field solving. The aerodynamic performances are researched to verify the spillage-adaptive feature of the new design concept.

\section{Analysis and the Candidate Solution for Inlet Start Issues}

As mentioned in the introduction, the exceeding of the swallowed mass to inlet flow capacity is the direct cause of inlet unstart. Hence, the improvement of inlet start performance is considered in the corresponding aspects: The side-embedded shock effects (SES) and the incident shock strength. The former is related to the flow capacity decrease and the latter is related to low spillage ability. 


\subsection{SES Effects Caused by Overlarge Lateral Compression}

The SES is observed in the authors' previous work [5] on a typical central-spillage bump inlet, which is demonstrated in Figure 1. The inflow is expanded over the bump and compressed in the inlet. The $z$-direction flow deflection of this inflow is larger than that of the parallel inflow. Accordingly, the lateral compression is larger. The compression is equivalent to the oblique shock wave of $M_{\infty}=5, \beta=12.31^{\circ}$, which forms a SES near the inlet bottom surface. The shock profile is clearly observed by the boundary between yellow and red colors. The SES effects will deteriorate the inlet performance in two aspects: (1) The internal shock system of the inlet distorts owing to the SES, which brings the additional energy loss; (2) the effective circulation area decreases, which forms an aerodynamic throat. Therefore, the flow capacity decreases and the inlet unstart can be easily induced.
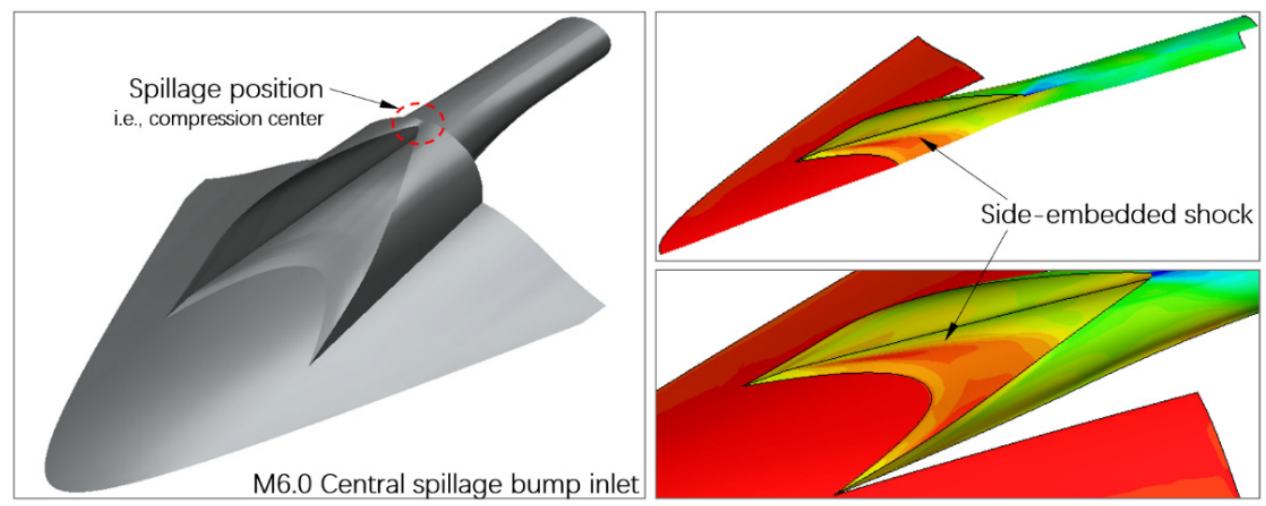

Figure 1. SES effects observed at the bottom surface of a central-spillage bump inlet.

\subsection{Modular Assessment Approach for the Spillage Pattern Analysis}

The direct cause for flow spillage is the detachment of the inlet incident shock. This section employs a modular assessment approach to estimate the spillage window area at low speed conditions. As shown in Figure 2, the lower-left mode stands for the typical central spillage pattern, and the upper-right mode stands for the side spillage pattern. The flat plane ABCD at the bottom represents the original incident shock of the inlet. At low speed conditions, the incident shock will detach from the compression center (e.g., points $\mathrm{O}_{1}$ and $\mathrm{A}_{1} / \mathrm{B}_{1}$ ). The spillage window then forms between the leading edge $C D$ and the compression center (shown as the red-colored part in the figure). AOPC and BOPD are two unit-squares for simplicity. The detailed analysis is as follows: (1) the bottom line $\mathrm{CD}$ is identical for two patterns. This notion indicates that the areas of spillage windows are determined by the track length of compression centers $L_{\mathrm{cc}}$ (e.g., curves $\mathrm{OO}_{1}$ and $\left.\mathrm{AA}_{1} / \mathrm{BB}_{1}\right)$. (2) The hypotenuse of the spillage window (e.g., $\mathrm{O}_{1} \mathrm{C}$ and $\mathrm{A}_{1} \mathrm{C}$ ) represents the streamwise span between the leading edge and the compression center. Specifically, the longer hypotenuse is led from a larger contraction ratio (i.e., a stronger incident shock). (3) In these two patterns with an identical inlet width space, the shock strength of central spillage pattern is larger than that of the side spillage pattern $\left(\mathrm{O}_{1} \mathrm{C}>\mathrm{A}_{1} \mathrm{C}\right)$. The $L_{\mathrm{cc}}$ of central spillage pattern is longer than that of the side spillage pattern, which leads to better spillage ability of the latter at the wide low speed range. As analyzed above, the side-spillage pattern holds larger potentials in flow spillage ability at low speed conditions. 


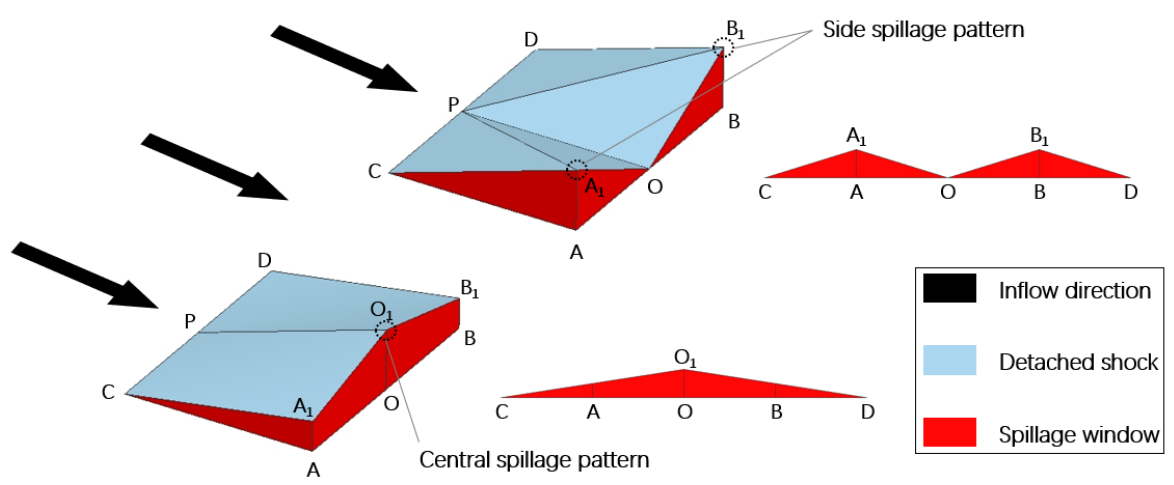

Figure 2. Modular assessments of two spillage patterns for bump inlet integration.

\subsection{Novel Spillage-Adaptive Integration Pattern}

The novel concept of the spillage-adaptive integration pattern is proposed based on the analysis in Sections 2.1 and 2.2. Figure 3 demonstrates that the pattern consists of the pressure-controllable bump and two symmetrical side-located inlets. The pressurecontrollable bump is the transition part between the airframe and the inlets. The parabolic profile of bump leading edge is flexible to be integrated with various airframes. In contrast with the conventional streamline-tracing bump, the pressure-controllable bump is inversely generated by the prescribed pressure distribution. Its pressure distribution controls the boundary layer diversion and the flow uniformity. Two inward-turning inlets are set back-to-back along the central plane of the bump. The region after the red-ribbon area in Figure 3 is the inlet presetting position. This region is designed to be occupied with high-momentum fluid. The flow uniformity is adjusted from expanded to parallel.

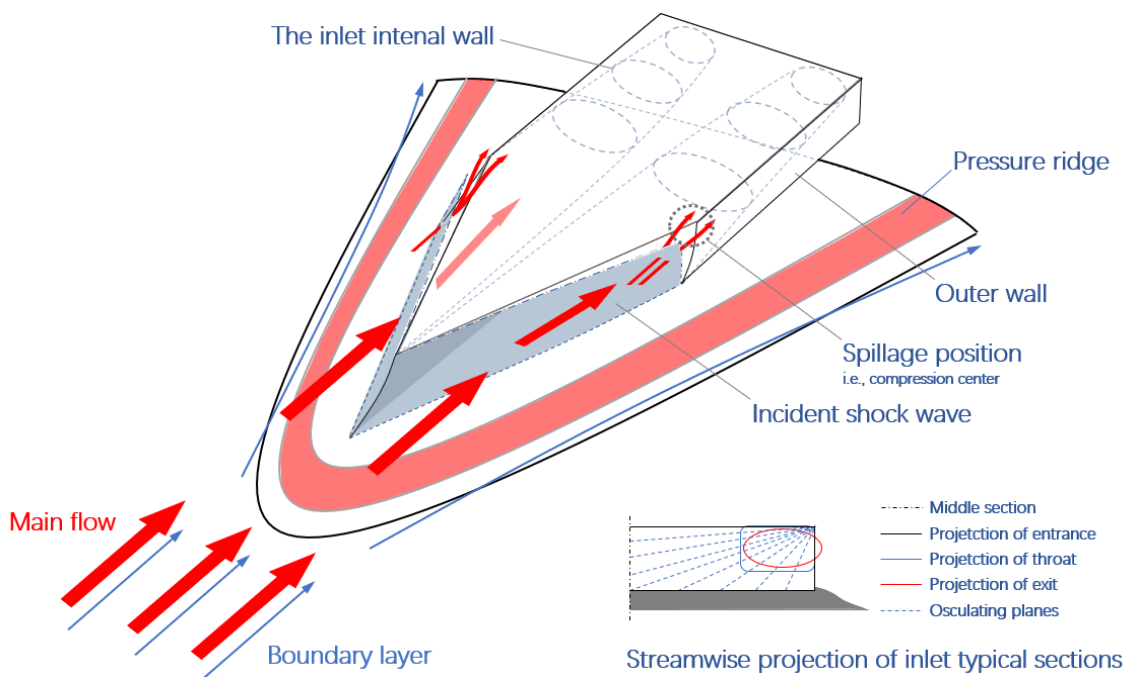

Figure 3. New spillage-adaptive integration concept with the wide speed range.

\section{Integrated Design of the Spillage-Adaptive Bump Inlet}

The integrated design method of the spillage-adaptive bump inlet is presented in this section. The pressure-controllable bump is inversely designed by the prescribed surface distribution. The inlets are designed on the basis of the classical osculating plane theory. The framework of the design is shown in Figure 4. 


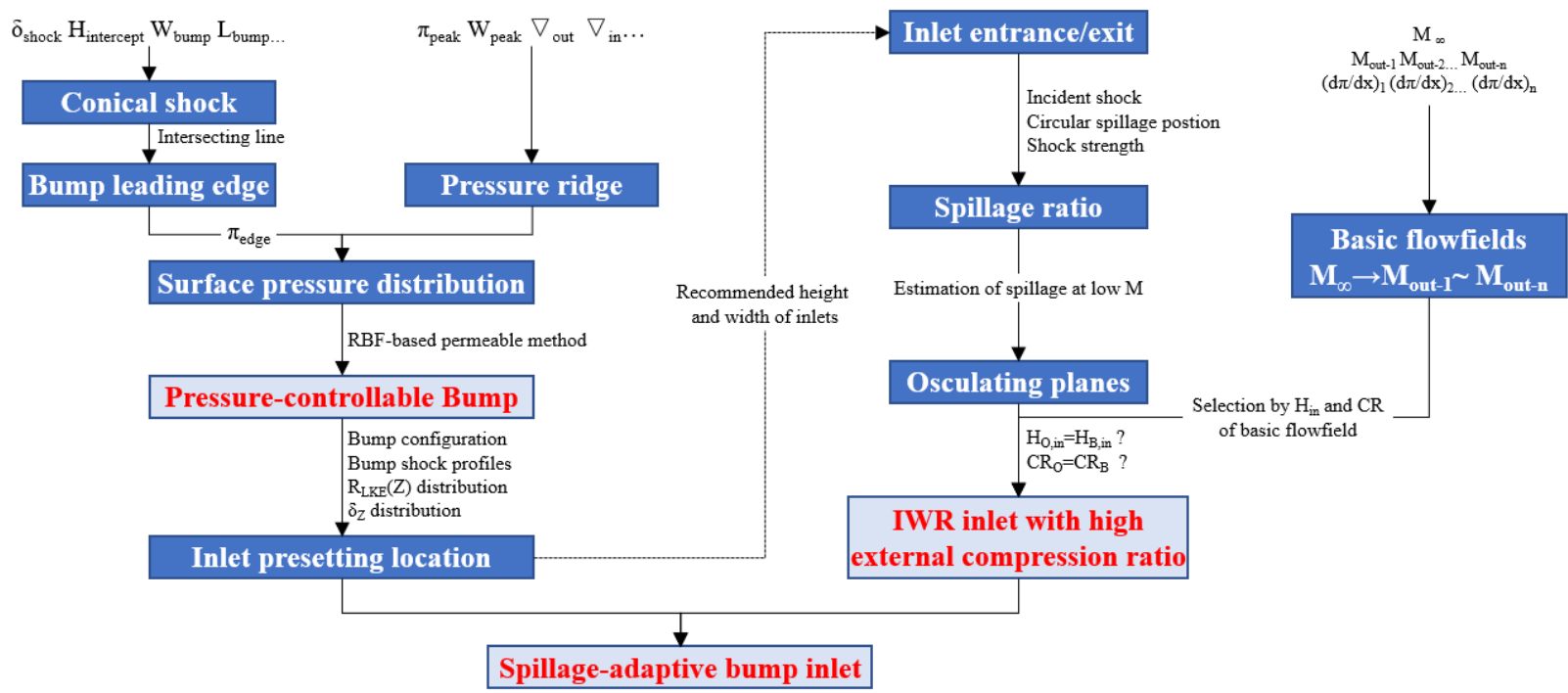

Figure 4. Schematic of the spillage-adaptive bump-inlet integration design.

The design of the pressure-controllable bump includes the leading edge and the surface pressure distribution. The four design parameters of the bump leading edge are the cone-shock angle $\delta_{\text {shock}}$, the intercepting height $H_{\text {intercept }}$, the bump width $W_{\text {bump }}$, and the bump length $L_{\text {bump }}$. The $\delta_{\text {shock }}$ is determined by the freestream speed and the derived cone angle, which can be calculated by the axisymmetric conical shock equations. The leading edge is obtained by the intersection of the conical shock wave and intercept plane. In this study, the planes parallel to xoy are taken as the intercept plane. The $H_{\text {intercept }}$ is the height between the intercepting plane and the central line. The $W_{\text {bump }}$ and $L_{\text {bump }}$ are two related parameters. Herein, the bump leading edge is uniquely determined when $\delta_{\text {shock }}, H_{\text {intercept }}$, and $W_{\text {bump }}$ (or $L_{\text {bump }}$ ) are fixed.

The PR mechanism is used for the bump surface pressure distribution. The PR concept originated from the mountain ridge, which blocks the wind near the ground from blowing to the other side of the mountain. A relatively high-pressure area is also set on the bump surface. The pressure is higher than that of both sides, thus making it like a ridge of pressure. The boundary layer is diverted by the outward pressure gradient $\nabla$ out. The flow direction is adjusted from expanded to parallel by the inward pressure gradient $\nabla$ in. The $\pi_{\text {peak }}$ is the peak value of PR, and the $W_{\text {peak }}$ is the width of PR.

The RBF-based (RBF: radius-based function) permeable boundary method [34] is previously developed to generate a bump surface with the PR pressure distribution. The classical permeable boundary method requires strict mesh topology, which is commonly applied in 2D aeronautical impeller design. The calculating efficiency and accuracy are seriously restricted in 3D surface with arbitrary pressure distribution. The previous study of authors coupled the permeable boundary method with the RBF network. The aerodynamic values of every single point on the bump surface are obtained by the interpolation of the reference points. The interpolation uses radius weighting to determine the values of solution points, which ensures the flow continuity and has better physical sense than other mathematical interpolation methods.

The inlet presetting location is determined on the basis of the bump flow field. The HKE flow ratio and the flow uniformity are two main aspects to be evaluated. As previously mentioned, the boundary layer diversion depends on $\nabla$ out and the flow uniformity depends on $\nabla_{\text {in }}$. Variables $\nabla_{\text {out }}$ and $\nabla_{\text {in }}$ are designed for the corresponding boundary layer thickness and the flow expansion ratio. The schematic of the inlet presetting location is shown in Figure 5 with the translucent red part. The upper boundary is the bump shock, the lower boundary is the bump surface, and the left/right boundaries are the HKE flow regions that are within the PR. The inlet lip (i.e., the inlet entrance) should be set in this region and capture the certain amount of mass flow for the engine. The area of inlet exit is 
calculated by the streamwise projected area of inlet lip and the contraction ratio. While the shape of inlet exit is assigned by the combustion chamber.

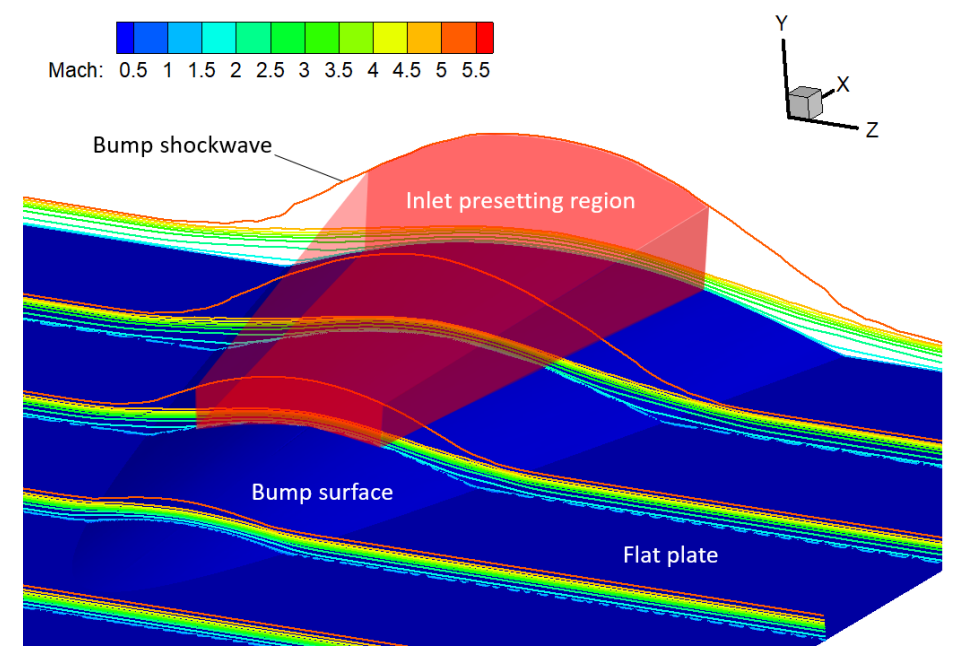

Figure 5. Inlet presetting region over the bump surface.

A coefficient $R_{\mathrm{LKE}}$ to evaluate the low kinetic energy (LKE) flow ratio of the reference inlet entrance is proposed in this study. This factor is the equivalent LKE flow area divided by the area between shock and bump, that indicates the usage of the inlet presetting region. The definition is as follows:

$$
R_{\mathrm{LKE}}(W)=\frac{\int_{0}^{W} H_{\mathrm{KE}}(z) \mathrm{d} z}{\int_{0}^{W}\left(y_{\text {shock }}(z)-y_{\text {bump }}(z)\right) \mathrm{d} z},
$$

where $W$ is the prescribed width of inlet, $y_{\text {shock }}(z)$ is the $y$-coordinate of shock position at a specific $z$-coordinate, $y_{\text {bump }}(z)$ is the $y$-coordinate of bump surface at a specific $z$-coordinate, $H_{\mathrm{KE}}$ is the equivalent thickness of the kinetic energy loss, which converts the kinetic energy loss to an equivalent thickness in the inviscid condition. This factor is defined as:

$$
H_{\mathrm{KE}}=\frac{\int_{0}^{\infty} \rho u\left(1-\eta_{\mathrm{KE}}\right) \mathrm{d} y}{\rho_{\infty} u_{\infty}},
$$

where $\rho, u$ are density and $x$-direction speed and $\rho_{\infty}, u_{\infty}$ are the parameters of freestream. The $\eta_{\mathrm{KE}}$ is the kinetic energy efficiency and is defined as:

$$
\eta_{\mathrm{KE}}=\frac{1}{\frac{\gamma-1}{2} M_{\infty}^{2}}\left(\frac{T^{*}}{T_{\infty}^{*}}\right)\left(1+\frac{\gamma-1}{2} M_{\infty}^{2}-\sigma^{\frac{1-\gamma}{\gamma}}\right),
$$

where $\gamma$ is the specific heat ratio, $T^{*}$ is the temperature, $\sigma$ is the total pressure recovery. $R_{\mathrm{LKE}}$ distribution at the inlet presetting region is shown in Figure 6. The abscissa is the half width of the inlet. The bump width is $0.698 \mathrm{~m}$. The $R_{\mathrm{LKE}}$ is lower than 0.0113 when $W<0.2 \mathrm{~m}$, which indicates that the boundary layer is well diverted, and the HKE occupies most of the region. The $R_{\mathrm{LKE}}$ is larger than 0.0113 when $W>0.2 \mathrm{~m}$, which indicates that the boundary layer diversion ratio is small. The distribution of $R_{\mathrm{LKE}}$ is flat when $W<0.2 \mathrm{~m}$, but it rapidly increases when $W>0.2 \mathrm{~m}$. The inlet width is finally determined as $0.4 \mathrm{~m}$. 


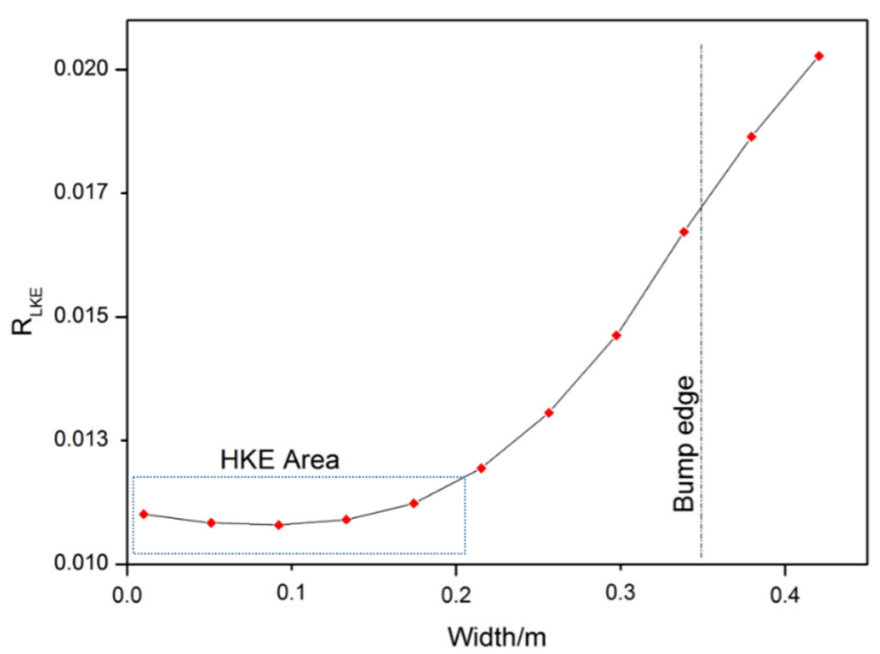

Figure 6. Ratio of LKE flow $\left(R_{\mathrm{LKE}}\right)$ distribution at the inlet presetting region.

With regard to the inlet subjected to the uniform inflow, the arrangement of osculating planes is the key factor to the inlet spillage at lower speed. The pre-compression strength of the inlet integrated with the forebody is another crucial aspect to be concerned about. The vertical compressing component is larger than the horizontal compressing component due to the elliptical shape of the bump shock. The incident shock detaches from the inlet lip and further distorts while the inflow speed decreases. The detached shock will vertically interact with the bump shock first and then horizontally. Hence, the side spillage pattern of the identical inlet contraction ratio is preferable to the bump inlet integration, which confirms better spillage ability in the low speeds. The spillage ratio and the mass capturing ratio can be balanced by different side spillage locations on the inlet lip.

The projection of the entrance and exit for the new spillage-adaptive inlet is shown in Figure 7. Line $\mathrm{AB}$ is the connecting part of two inlets. The solid black line is the projection of the inlet entrance on the $x$-direction. Meanwhile, the solid red line is the projection of the inlet exit. Point $\mathrm{O}$ is the compression center of the inlet. The ratio of projection length between $\mathrm{AB}$ and $\mathrm{BC}$ is 1.02, which confirms that the inlet lip is within the presetting location (Figure 5). The contraction ratio of the projected area of the entrance and exit is 3.65 , of which the contraction ratio from point $\mathrm{A}^{\prime}$ to $\mathrm{A}^{\prime}$ is 2.80 , the contraction ratio from point $B$ to $B^{\prime}$ is 2.07 , and the contraction ratio from point $C$ to $C^{\prime}$ is 2.17 . The contraction ratio of typical positions $\mathrm{AA}^{\prime}, \mathrm{BB}^{\prime}$, and $\mathrm{CC}^{\prime}$ is relatively uniform, which can weaken the lateral compression wave intensity between the rear section of the compression section of the inlet to a certain extent. The projection of exit profile is circular, and the AOC is a spline. The entrance curve AOC is tangent to the outlet curve $\mathrm{A}^{\prime} \mathrm{OC}^{\prime}$ at point $\mathrm{O}$. Thus, the inlet will not produce additional external drag. 


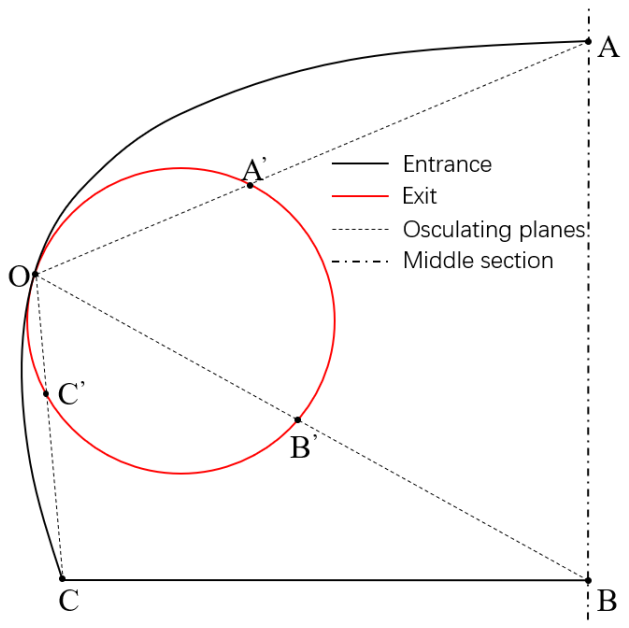

Figure 7. Osculating planes for the new spillage-adaptive inlet.

The high external compression ratio basic flow field for designing the IWR inlet is developed in the authors' previous study [16], which has proved its efficiency for M 3.5 inflow condition. This study uses the same approach to improve the flow field in M 6.0 condition. The typical internal conical flow field (ICFC) is shown in the left subplot of Figure 8. A large expansion zone can be observed at the entrance of the compression section. The Mach number increases from 5.2 to 5.3 and then decreases to 5.2, which brings an additional oblique shock wave at $x=4$ in the basic flow field. On the one hand, the interaction between shocks is introduced to increase the energy loss. On the other hand, the expanded flow reduces the compression efficiency. Therefore, the flow field length required to obtain the same Mach number at the exit is larger. In contrast with the basic flow field of ICFC, the basic flow field of the new ICFC+ achieves the following improvements: (1) the ICFC+ flow field improves the intensity of the upstream initial shock wave. Accordingly, the incident point of the initial shock wave is moved from 3.6 to 3.4, and the Mach number after the wave is reduced from the original 5.3 to 5.1 ; (2) in the initial section of the ICFC+ flow field, the expansion zone has been eliminated, and the initial section of the basic flow field is from the original two channels. The incident shock is simplified as an incident shock. The Mach number distribution along the path demonstrates that the Mach number of the wall corresponding to $x$ coordinate of the ICFC + flow field is at least 0.1 lower than that of the ICFC flow field, maintaining a good compression efficiency; (3) the length of the flow field is five for the ICFC flow field to compress the flow from M 6.0 to 3.2, while the length of the flow field is 4.6 for the ICFC+ flow field to compress the flow from M 6.0 to 3.1. The basic flow field is shortened by $8 \%$, which indicates that the new ICFC+ flow field greatly improves the compression efficiency by eliminating the upstream expansion zone and shortens the flow field length required to achieve the same compression performance.
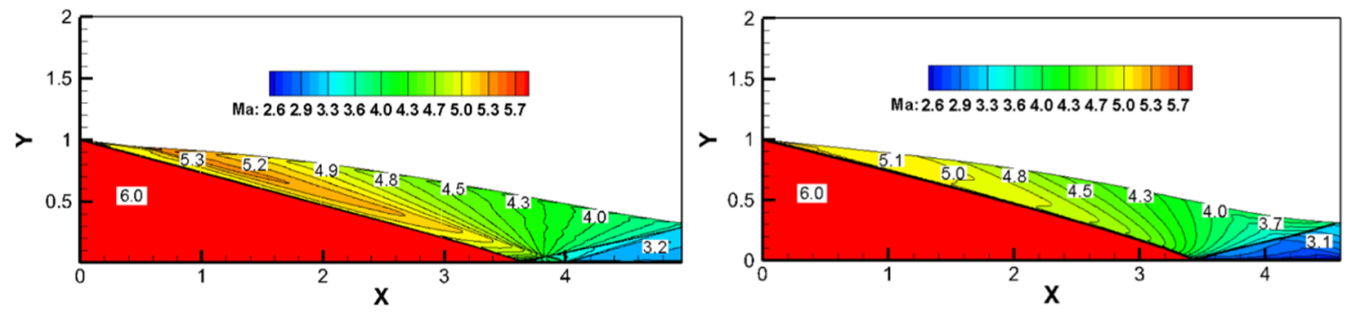

Figure 8. Improvement of the high-external-ratio basic flow field: ICFC (left) and ICFC+ (right).

The configuration of the new spillage-adaptive bump inlet is shown in Figure 9. The two inlet channels of the double channel lateral overflow scheme are symmetrically placed back-to-back, and the inlet profile is completely located within the PR region. The 
dimensions of the bump inlet are $2371 \mathrm{~mm} \times 1161 \mathrm{~mm} \times 265 \mathrm{~mm}$. The shape of the bump inlet is connected with the flat plate in this work to simplify the flow field analysis with low energy flow and study the performance of the inlet with different boundary layer thicknesses.

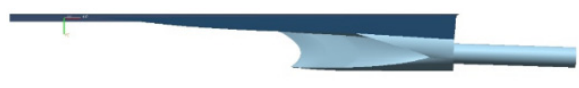

Side view

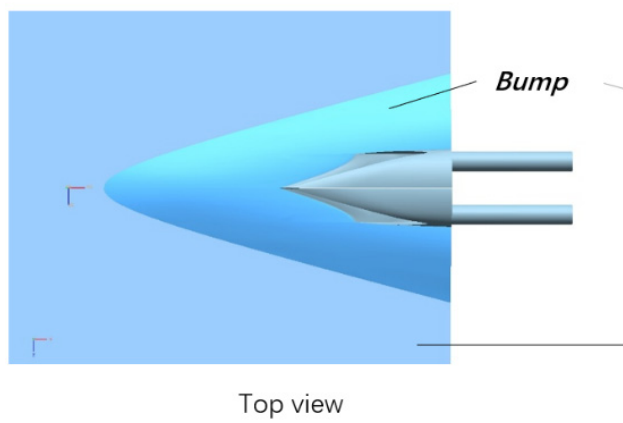

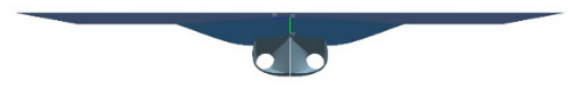

Front view

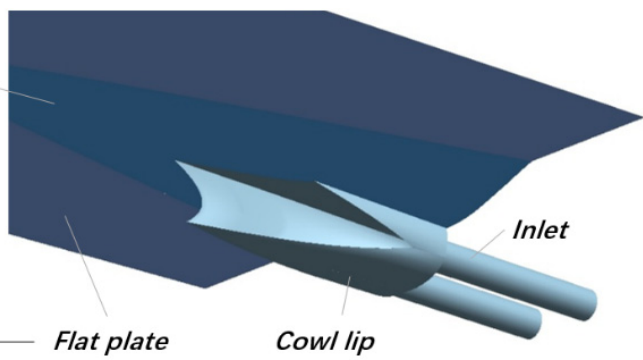

$3 \mathrm{D}$ view

Figure 9. Configuration of the new spillage-adaptive bump inlet.

\section{Aerodynamic Characteristics of the New Bump Inlet}

\subsection{Preparation of Numerical Simulation}

The design condition is M 6.0 at altitude $H=24 \mathrm{~km}$. The aerodynamic performance of the bump inlet was examined by viscous numerical simulations. The flow was modeled as the compressible steady flow using Reynolds-Averaged Navier-Stokes (RANS) equations simulated by the ANSYS CFX commercial software. The governing equations are demonstrated in the following form:

$$
\frac{\partial}{\partial t} \iiint_{\Omega} U \mathrm{~d} V+\iint_{\partial \Omega} \boldsymbol{F}_{\mathcal{C}} \cdot n \mathrm{~d} S-\iint_{\partial \Omega} \boldsymbol{F}_{v} \cdot n \mathrm{~d} S=0,
$$

where $\boldsymbol{U}$ is the conservative vector, $\boldsymbol{F}_{\mathrm{c}}$ is the convective flux vector, $\boldsymbol{F}_{\mathrm{v}}$ is the viscous flux vector, $n=\mathrm{n}_{\mathrm{x}} \boldsymbol{i}+\mathrm{n}_{\mathrm{y}} j+\mathrm{n}_{\mathrm{z}} k$ is the unit normal vector, $t$ is the time, $\Omega$ is the control volume, and $S$ is the control volume surface. The vectors $U, F_{\mathrm{C}}$, and $\boldsymbol{F}_{\mathrm{v}}$ are defined as:

$$
\boldsymbol{U}=\left\{\begin{array}{c}
\rho \\
\rho u \\
\rho v \\
\rho w \\
E
\end{array}\right\}, \boldsymbol{F}_{c}=\left\{\begin{array}{c}
\rho u \boldsymbol{i}+\rho v \boldsymbol{j}+\rho w \boldsymbol{k} \\
\left(\rho u^{2}+p\right) \boldsymbol{i}+\rho u v \boldsymbol{j}+\rho u w \boldsymbol{k} \\
\rho u v \boldsymbol{i}+\left(\rho v^{2}+p\right) \boldsymbol{j}+\rho v w \boldsymbol{k} \\
\rho u w \boldsymbol{i}+\rho v w \boldsymbol{j}+\left(\rho w^{2}+p\right) \boldsymbol{k} \\
(E+p) u \boldsymbol{i}+(E+p) v \boldsymbol{j}+(E+p) w \boldsymbol{k}
\end{array}\right\}, \boldsymbol{F}_{v}=\left\{\begin{array}{c}
0 \\
\tau_{x x} \boldsymbol{i}+\tau_{x y} \boldsymbol{j}+\tau_{x z} \boldsymbol{k} \\
\tau_{y x} \boldsymbol{i}+\tau_{y y} \boldsymbol{j}+\tau_{y z} \boldsymbol{k} \\
\tau_{z x} \boldsymbol{i}+\tau_{z y} \boldsymbol{j}+\tau_{z z} \boldsymbol{k} \\
\prod_{x} \boldsymbol{i}+\Pi_{y} \boldsymbol{j}+\Pi_{z} \boldsymbol{k}
\end{array}\right\},
$$

In the above equations, the $\rho$ is the density. The $u, v$, and $w$ are respectively the $x / y / z$ partial velocities on Cartesian coordinate system. The $E, p$, and $\tau$ are respectively the total energy per unit mass, the pressure, the viscous stress tensor. The $\Pi_{\mathrm{x}} \sim \Pi_{\mathrm{z}}$ are given by:

$$
\left\{\begin{array}{l}
\Pi_{x}=u \tau_{x x}+v \tau_{x y}+w \tau_{x z}+\lambda \frac{\partial T}{\partial x}, \\
\Pi_{y}=u \tau_{y x}+v \tau_{y y}+w \tau_{y z}+\lambda \frac{\partial T}{\partial y}, \\
\Pi_{z}=u \tau_{z x}+v \tau_{z y}+w \tau_{z z}+\lambda \frac{\partial T}{\partial z},
\end{array}\right.
$$

where the $T$ is the temperature and the $\lambda$ is the thermal conductivity.

The high-resolution scheme based on MUSCL (Monotonic Upstream-centered Scheme for Conservation Laws) reconstruction was employed to calculate the flux terms. That is, all results are calculated by CFX commercial software 2019 R3 based on high resolution in numeric turbulence and advection scheme. The calculation converges when the residuals are less than $1 \times 10^{-5}$. 
The simulation for mixed external-internal flow field is a special case to the turbulence model determination. Zhang et al. [35] studied the impacts of turbulence models on the numerical results. Both $\mathrm{k}-\varepsilon$ and Spalart-Allmaras turbulence models match well with experiment data of a 2D supersonic inlet, which contains external and internal flow field. The $\mathrm{k}-\varepsilon$ turbulence model was used in this study while considering both accuracy and efficiency. Besides, a previous research [36] obtained that in the simulation of hypersonic inlets, the calculation results branch between using variable and constant specific heat ratio at high speeds (approximately $M 4.0$ ), as shown in Figure 10. The difference between variable/fixed specific heat ratio cases can be ignored when $M<4.0$. When $M \geq 4.0$, the difference increases with $M$. The total temperature of fixed specific heat ratio is approximately $18 \%$ higher than that of variable specific heat ratio. Therefore, this study uses the variable specific heat ratio in the CFD simulation. Thus, the piecewise-polynomial method is chosen to calculate the specific heat and viscosity by the Sutherland law.

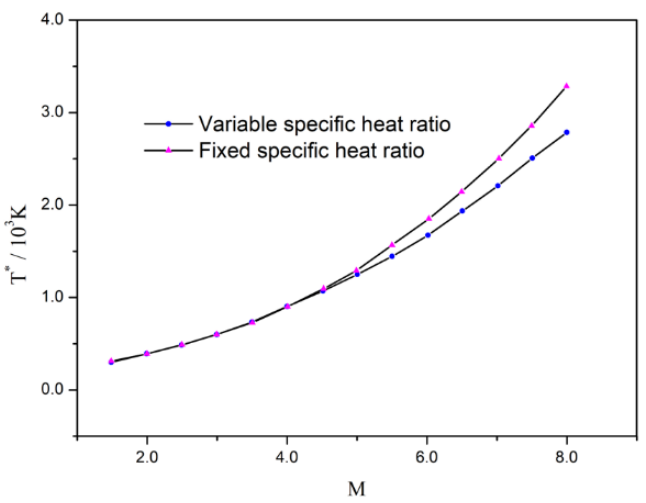

(a)

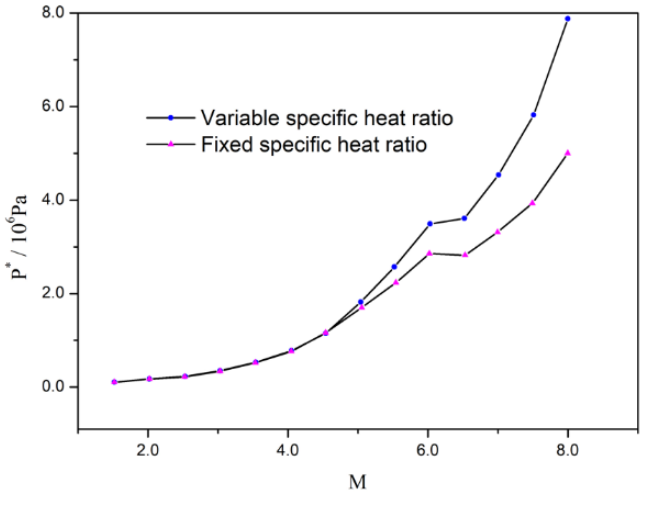

(b)

Figure 10. Results based on the fixed/variable specific heat ratio: (a) Total temperature $\mathrm{T}^{*}$ distribution; (b) Total pressure $\mathrm{P}^{*}$ distribution.

The 3D structured mesh is established for the numerical simulation, which is shown in Figure 11. A $3.5 \mathrm{~m}$ flat plate is set in front of the bump surface for boundary layer development, which is divided by four parts to create boundary layer with different thicknesses. The length of the four parts is successively $0.5,1.0,1.0,1.0 \mathrm{~m}$. That is, if the front two (purple and red) plates are set as free-slip wall condition and the rear two (yellow and green) plates are set as no-slip wall condition, the actual length for boundary layer development $\left(L_{\mathrm{BL}}\right)$ is $2.0 \mathrm{~m}$. Thereby, it can create inflow conditions with various nominal boundary layer thicknesses as 9.00, 21.05, 32.37, $41.72 \mathrm{~mm}$ at M 6.0, which are successively $5.1 \%, 11.8 \%, 18.2 \%, 23.4 \%$ of the inlet entrance height. To obtain the requested standard $\mathrm{k}-\varepsilon$ turbulence model, the minimum mesh height of near-wall grid is $0.15 \mathrm{~mm}$, and the grids in the $y$-direction are stretched with the increasing ratio of 1.2 refined with geometric proportion rule. The $y+$ is kept as $20 \sim 110$ to meet the standard $k-\varepsilon$ turbulence model. A C-grid is set to surround the bump, which accurately fits the bump leading edge. An O-grid is set in the internal flow field of inlet, which accurately fits the inlet wall. A grid independence study is conducted for the bump inlet configuration. The mesh ranging between 3.5 and 6.0 million is generated. The results are shown in Table 1. The $\sigma$ is the total pressure recovery, the $\pi$ is the static pressure ratio, which is calculated by the exit pressure divided by the freestream pressure. The $\varphi$ is the mass capturing ratio. All the aerodynamic characteristics in the current work are obtained by mass-averaged method on corresponding position (e.g., the freestream, the throat, the inlet exit, etc.,). Due to the aerodynamic characteristics discrepancy between different meshes, the reasonable mesh in the domain is approximately 4.3 million. 


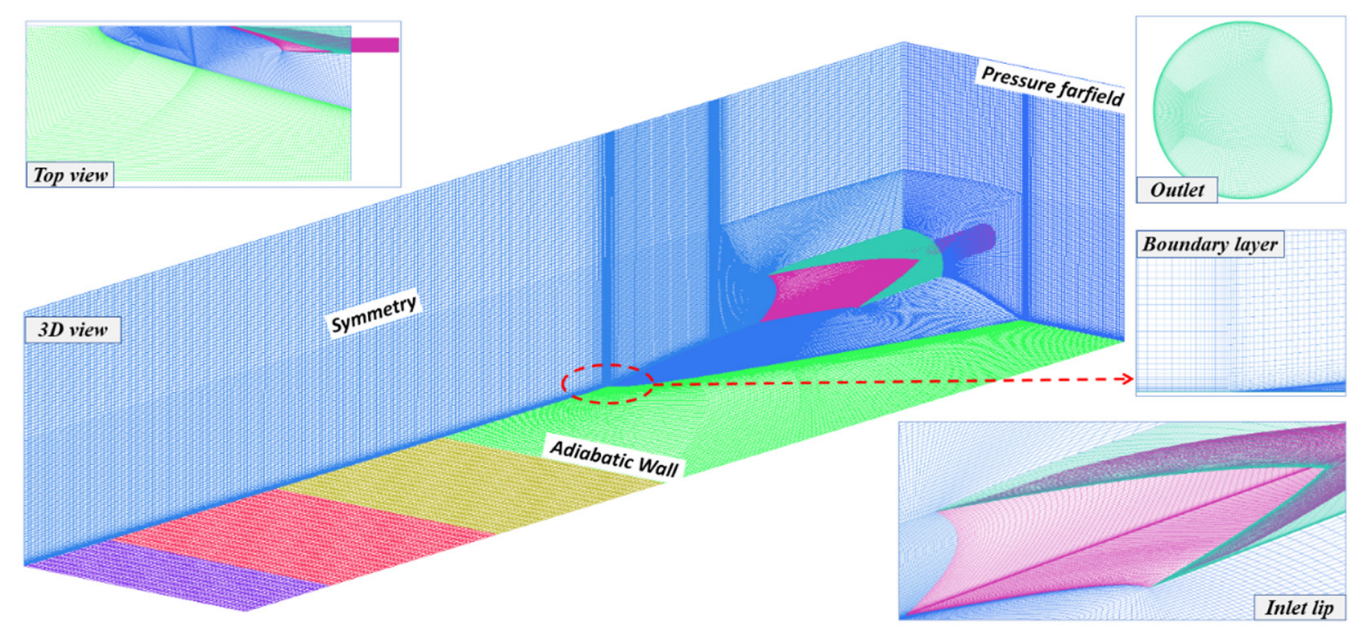

Figure 11. Structured mesh of the new spillage-adaptive bump inlet.

Table 1. Gird independence analysis $\left(M_{\infty}=6.0, H=24 \mathrm{~km}\right)$.

\begin{tabular}{cccccc}
\hline Type & Mesh Number & $\boldsymbol{\sigma}_{\text {exit }}$ & $\boldsymbol{\pi}_{\text {exit }}$ & $\boldsymbol{M}_{\text {exit }}$ & $\boldsymbol{\varphi}_{\text {throat }}$ \\
\hline Coarse grid & 3.5 million & 0.487 & 17.812 & 3.014 & 0.747 \\
Medium grid & 4.3 million & 0.489 & 18.371 & 3.018 & 0.748 \\
Fine grid & 6.0 million & 0.489 & 18.374 & 3.018 & 0.748 \\
\hline
\end{tabular}

The boundary settings for calculation are as follows. The no-slip and adiabatic wall conditions are adopted for entire walls, which include the bump inlet and the flat plate. The symmetry condition is adopted for the central plane and the freestream condition is adopted for the outer part of the whole calculating domain. The supersonic outlet condition is adopted for exit of the inlet. The numerical methods in this study have been effectively validated by You and Liang [37], who used wind tunnel experiments and showed that the method can calculate reasonable and reliable results. The numerical method has also been validated in the previous study [5] through a comparison with an experimental study of bump-inlet integration shown in Figure 12. The results show that the difference of static pressure between the numerical and the experimental results is less than 2.7, which indicates that the two results agree with each other. As validated above, the numerical methods effectively calculate the true flow field.

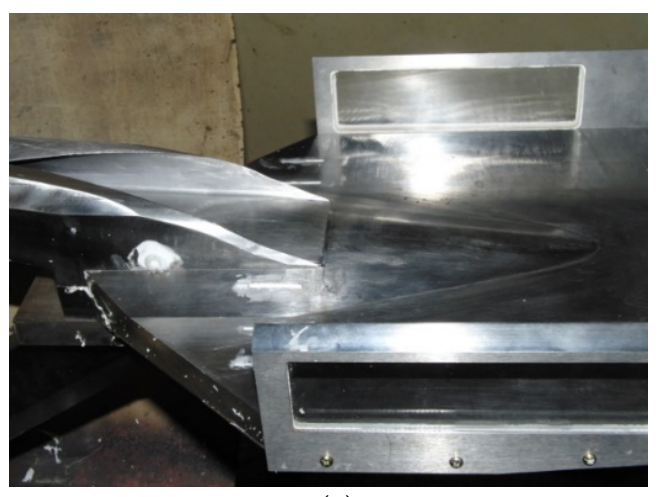

(a)

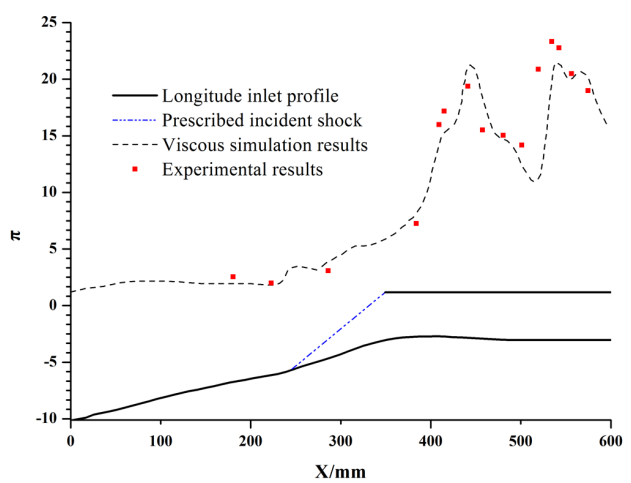

(b)

Figure 12. Validation of the numerical methods for the bump inlet integration ((a) M6 scaled wind tunnel test; (b) longitude pressure distribution of the experimental and numerical results). 


\subsection{Aerodynamic Characteristics of the Spillage-adaptive Integration at the Design Condition}

The aerodynamic characteristics of the new integration (pattern 1) are shown in Table 2. The results of the typical central spillage pattern (pattern 2) are also presented for comparison. The mass capturing ratio $\varphi_{1}$ is $0.4 \%$ higher than $\varphi_{2}$. The $M_{\text {exit, } 1}$ is $3.6 \%$ lower than $M_{\text {exit,2. }}$. The total pressure recovery $\sigma_{1}$ is $2.0 \%$ higher than $\sigma_{2}$. The exit static pressure $\pi_{1}$ is $7.1 \%$ lower than $\pi_{2}$. The $R_{\mathrm{M}}$ is the ratio of the deceleration, which is $M_{\text {exit }}$ divided by $M_{\infty}$. The kinetic energy efficiency $\eta_{\mathrm{KE}, 1}$ is almost the same with $\eta_{\mathrm{KE}, 2}$. The two integration patterns maintain similar performance in the design condition.

Table 2. Aerodynamic characteristics of bump inlets at $M_{\infty}=6.0$ and $H=24 \mathrm{~km}$.

\begin{tabular}{cccccccc}
\hline Spillage Position & $\boldsymbol{M}_{\infty}$ & $\boldsymbol{\varphi}_{\text {throat }}$ & $\boldsymbol{M}_{\text {exit }}$ & $\boldsymbol{\sigma}_{\text {exit }}$ & $\boldsymbol{\pi}_{\text {exit }}$ & $\boldsymbol{R}_{\mathbf{M}}$ & $\eta_{\mathrm{KE}}$ \\
\hline 1. Side spillage & $\mathbf{6 . 0}$ & $\mathbf{0 . 7 4 8}$ & $\mathbf{3 . 0 2}$ & $\mathbf{0 . 4 9}$ & $\mathbf{1 8 . 4}$ & $\mathbf{0 . 4 9 9}$ & $\mathbf{0 . 9 6 9}$ \\
2. Central spillage & 6.0 & 0.745 & 2.94 & 0.48 & 17.1 & 0.487 & 0.968 \\
\hline
\end{tabular}

The flow structure of the new spillage-adaptive bump inlet is shown in Figure 13. The pressure contours of the bump, cowl lip, and inlet are presented. The M contours of various crosswise-sections along the $x$-direction are also obtained. The detailed analysis is as follows. (1) The boundary layer develops along the $x$-direction, and its thickness increases. Once the layer is encountered with the bump surface, it is diverted by $\nabla$ out and accumulates at the corner between the bump and the flat plate. (2) The inlets are located after the bump shock; thus, no interaction exists between the bump shock and the incident shock at design condition. Meanwhile, the LKE flow affects the two shocks. The bump shock and the incident shock distort by the influence of the LKE flow. The bump shock has not attached well to the leading edge. The incident shock distorts upstream, which decreases the mass capturing ratio. (3) The PR mechanism and the side spillage pattern demonstrate that the streamlines at the inlet bottom wall are uniform. No concentrating trend can be observed for the streamlines. This notion indicates that the flow field of inlet is uniform to avoid overlarge side compression. Specifically, the SES effects (Section 2.1) are avoided in the new bump inlet.

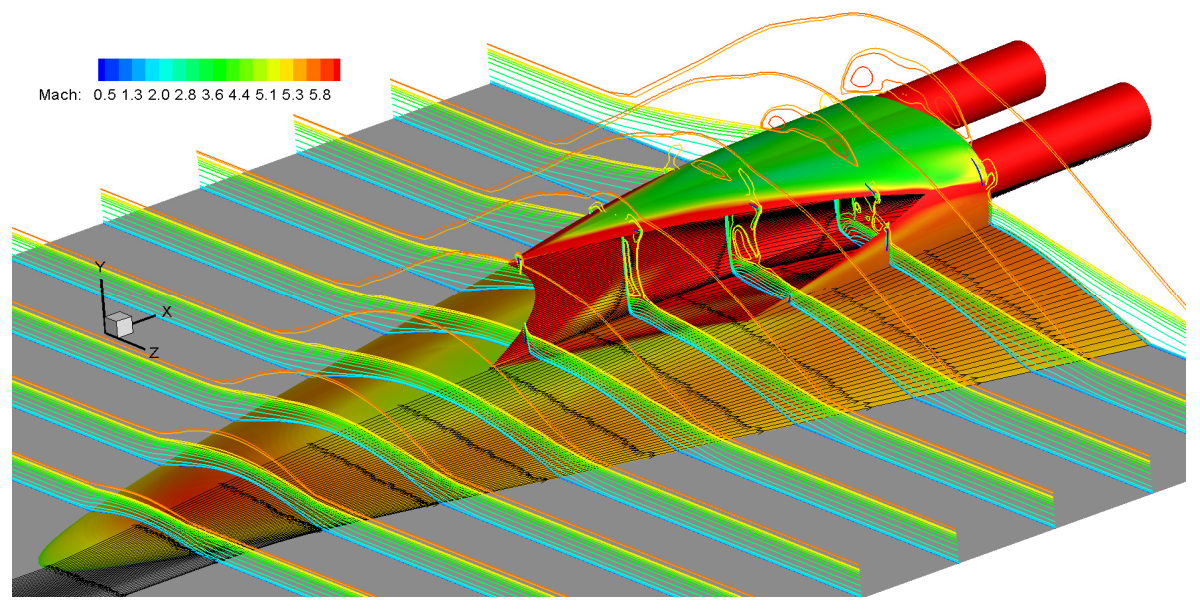

Figure 13. Flow structure of the new spillage-adaptive bump inlet.

\subsection{Start-Ability of the New Spillage-Adaptive Bump Inlet}

The new bump inlet is numerically studied at M 2.0-6.0 to investigate the speed range. In Table 3, the swallowed mass has not exceeded the inlet flow capacity. Meanwhile, the compression ratio of M 2.0 is 3.6, which is $56 \%$ lower than that of M 2.5 condition. This value is particularly low to bear the pressure fluctuation from the downstream combustor. Thus, the inlet speed range is M 2.5-6.0. The incident shock distorts toward the lip, and the flow spillage increases with the decrease in inflow speed. The compression efficiency of the 
inlet decreases; hence, the $\pi_{\text {exit }}$ decreases. At low speeds, the actual capture area of the inlet decreases with the increase in spillage. The actual contraction ratio of the inlet decreases which results in reduction in $\pi_{\text {exit }}$. The shock system is affected by the flow spillage, and variables $\sigma$ and $\eta_{\mathrm{KE}}$ decrease.

Table 3. Start-ability of the spillage-adaptive inlet.

\begin{tabular}{cccccccc}
\hline $\boldsymbol{M}_{\infty}$ & $\boldsymbol{\varphi}_{\text {throat }}$ & $\boldsymbol{\varphi}_{\text {spillage }}$ & $\boldsymbol{M}_{\text {exit }}$ & $\boldsymbol{\sigma}_{\text {exit }}$ & $\boldsymbol{\pi}_{\text {exit }}$ & $\boldsymbol{R}_{\mathbf{M}}$ & $\eta_{\text {KE }}$ \\
\hline $\mathbf{6 . 0}$ & 0.748 & 0 & 3.02 & 0.49 & 18.4 & 0.499 & 0.969 \\
$\mathbf{5 . 0}$ & 0.676 & $9.5 \%$ & 2.49 & 0.53 & 13.0 & 0.497 & 0.961 \\
$\mathbf{4 . 0}$ & 0.547 & $26.8 \%$ & 1.78 & 0.45 & 11.1 & 0.445 & 0.921 \\
$\mathbf{3 . 5}$ & 0.508 & $32.1 \%$ & 1.53 & 0.53 & 9.9 & 0.437 & 0.920 \\
$\mathbf{3 . 0}$ & 0.459 & $38.6 \%$ & 1.22 & 0.64 & 9.2 & 0.405 & 0.927 \\
$\mathbf{2 . 5}$ & 0.339 & $54.6 \%$ & 0.81 & 0.75 & 8.2 & 0.324 & 0.933 \\
$\mathbf{2 . 0}$ & 0.253 & $66.1 \%$ & 0.95 & 0.83 & 3.6 & 0.475 & 0.931 \\
\hline
\end{tabular}

The spillage ratio $\varphi_{\text {spillage }}$ is used in this work to better analyze the influence of flow spillage on the inlet start-ability. This concept is defined as the spilled mass flow of the low speed condition $\left(\dot{m}_{\text {designcondition }}-\dot{m}_{\text {low Mach condition }}\right)$ divided by that of the design condition ( $\left.\dot{m}_{\text {designcondition }}\right)$. The equation is given by:

$$
\varphi_{\text {spillage }}=1-\frac{\dot{m}_{\text {low Mach condition }}}{\dot{m}_{\text {designcondition }}},
$$

The $\varphi_{\text {spillage }}-M_{\infty}$ distribution is shown in Figure 14. The analysis is as follows: (1) the relationship between two parameters is quasi-parabolic. (2) The $\varphi_{\text {spillage }}$ decreases by $9.5 \%$ when the $M_{\infty}$ decreases from 6.0 to 5.0 . This value decreases by $17.3 \%$ when the $M_{\infty}$ decreases from 5.0 to 4.0 . The $\sigma_{\text {throat }}$ at $M_{\infty}=4.0$ is $15.0 \%$ lower than that at $M_{\infty}=6.0$. The $\sigma_{\text {exit }}$ at $M_{\infty}=4.0$ is $8.1 \%$ lower than that at $M_{\infty}=6.0$. The results reveal that the main energy loss by the flow spillage is caused at the inlet compression section. The incident shock and the spillage are the main cause of the energy loss for the low speed conditions. (3) The $\varphi_{\text {spillage }}$ increases by $11.8 \%$ between $M_{\infty}=4.0$ and 3.0. This factor increases by $16.0 \%$ between $M_{\infty}=3.0$ and 2.5. The flow spillage is high at $M_{\infty}>4.0$ and $M_{\infty}<3.0$, while it is relatively lower between $M_{\infty}=3.0$ and 4.0, which shows less sensitivity of incident shock distortion at this speed range.

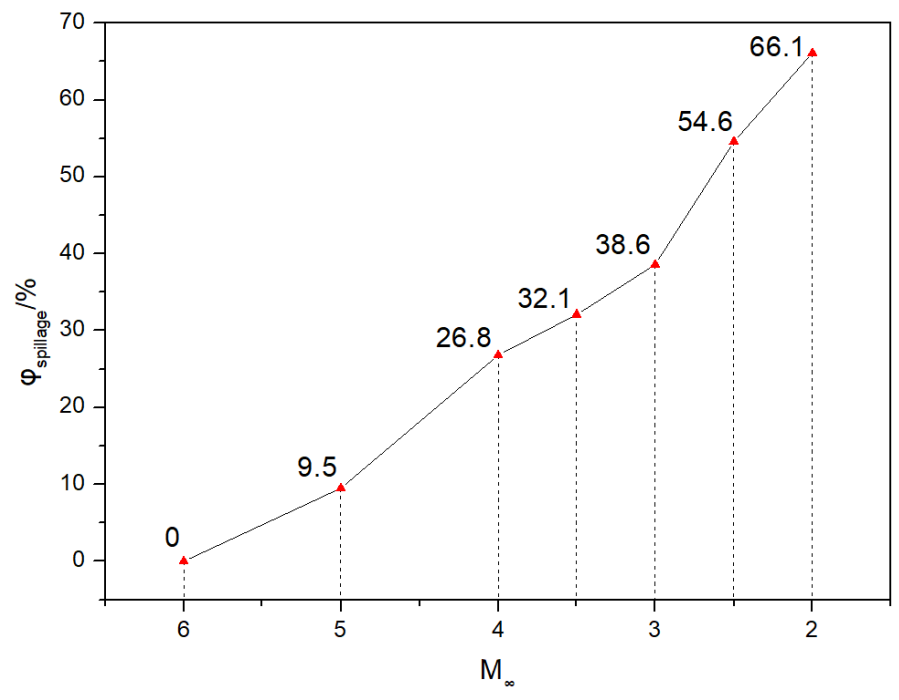

Figure 14. Impact of different Mach numbers to $\varphi_{\text {spillage }}$. 
The incident shock systems at low speed conditions $\left(M_{\infty}=2.0-5.0\right)$ are demonstrated in Figure 15, which shows the interaction between the incident shock and the thick boundary layer $\left(L_{\mathrm{BL}}=3.5 \mathrm{~m}\right)$. The detailed analysis is as follows: 1$)$ the shock system of $M_{\infty}=5.0$ is similar to that of $M_{\infty}=6.0$ (shown in Figure 13). Flow spillage (9.5\%) occurs at the upper part of the inlet lip. 2) When $M_{\infty}$ decreases to 4.0 , the spillage increases by $26.8 \%$ than the design condition. The incident shock distorts the upstream to make a spillage window at the compression center and the side wall of the inlet. The LKE fluid accumulates around the side wall. This phenomenon restricts the flow capacity by forming an aerodynamic throat that is smaller in area than the geometry. 3) The decrease in $M_{\infty}$ leads to the main flow spilling from the adjacent region of the compression center. Two impact patterns of spillage to the flow field can be observed. In the speed range of M 3.0 to 5.0, the spillage ratio is lower than $40 \%$. The spilled flow has not encountered bump shock. In the speed range of M 2.0 to 3.0, the spillage ratio is over $40 \%$. The interaction between the inlet incident shock and the bump shock leads to the change in the external flow field, which can be observed on the middle section (colored in red).

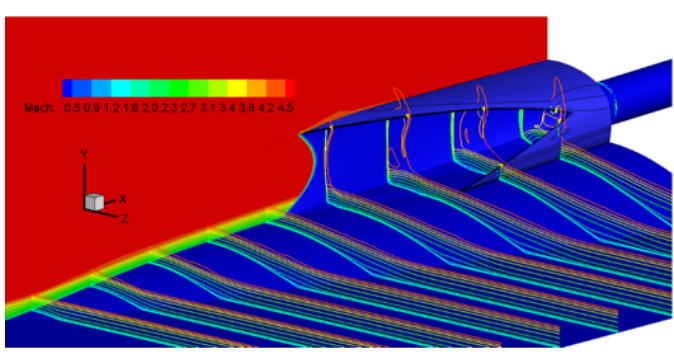

(a)

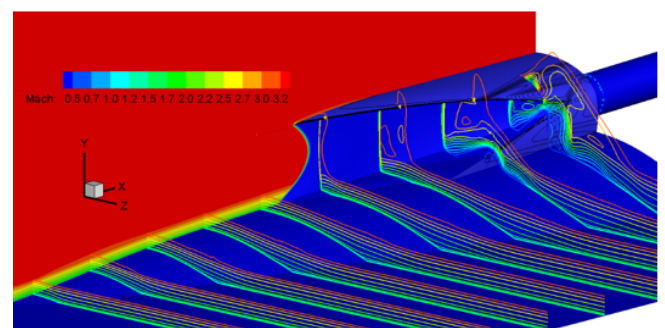

(c)

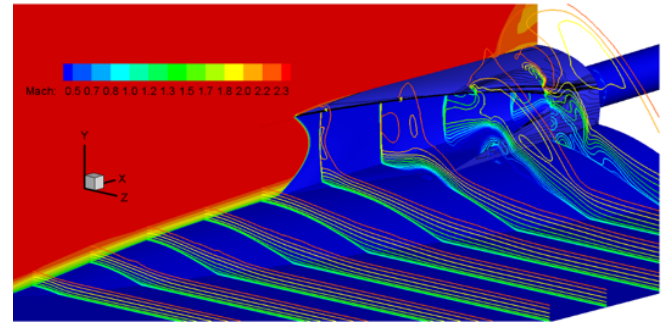

(e)

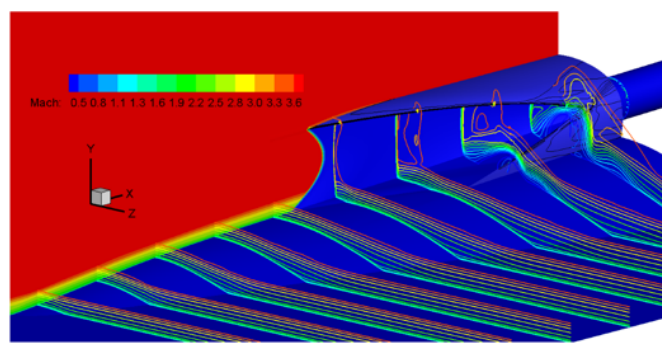

(b)

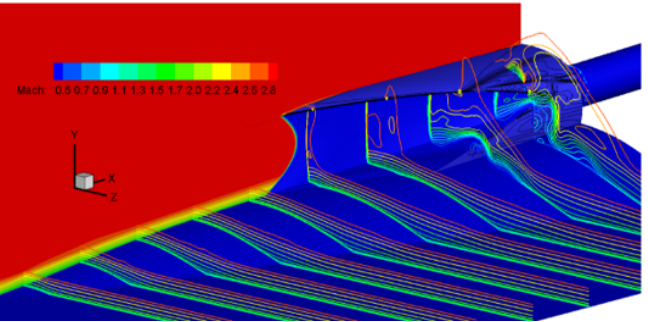

(d)

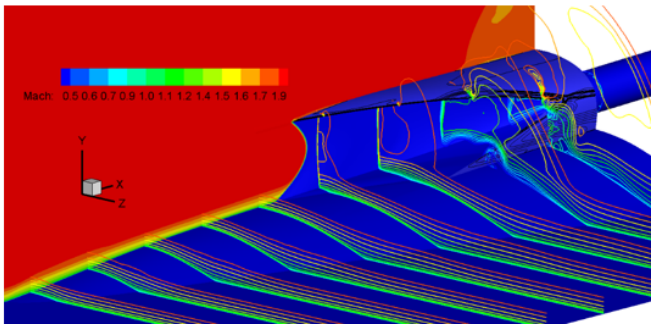

(f)

Figure 15. Incident shock system at low speed conditions $\left(L_{\mathrm{BL}}=3.5 \mathrm{~m}\right) .(\mathbf{a}) M_{\infty}=5.0 ;(\mathbf{b}) M_{\infty}=4.0 ;(\mathbf{c}) M_{\infty}=3.5 ;(\mathbf{d}) M_{\infty}=3.0$; (e) $M_{\infty}=2.5 ;$ (f) $M_{\infty}=2.0$.

\subsection{Effects of Boundary Layer Thickness to Aerodynamic Characteristics}

The aerodynamic characteristics of the inlet under different boundary layer thicknesses are shown in Figure 16. The $L_{\mathrm{BL}}$ is the length for boundary layer development. When the $L_{\mathrm{BL}}$ decreases from 3.5 to $1.0 \mathrm{~m}$, the LKE ratio of the captured inflow decreases. Accordingly, the $M_{\text {exit }}$ and $\sigma$ increase, and the gradient of these two parameters decrease with the $L_{\mathrm{BL}}$. This phenomenon can be explained on the basis of the boundary layer thickness. The nominal boundary layer thickness $\delta$ (i.e., the height where $99 \%$ of mainstream speed 
locates) is positively correlated to the development length of boundary layer, which is shown as,

$$
\delta \propto \sqrt{v x / U}
$$

where $v$ is the kinetic viscosity coefficient, $x$ is the length for boundary layer development, $U$ is the mainstream speed. When $v$ and $U$ are fixed, $x$ and $\delta$ are in parabolic relation. Variable $x$ stands for $L_{\mathrm{BL}}$ in this study, and $\delta$ denotes the boundary layer thickness. Considering $0<\delta<1$, the decrease in $x$ will lead to the decrease in $\delta$. When $L_{\mathrm{BL}}$ decreases with the identical $\Delta x$, the $\sigma$ will increase, but the $\Delta \sigma$ will decrease. This condition explains the trend in Figure 16b. The Mach number will increase with the decrease in $L_{\mathrm{BL}}$, but $\Delta M$ will decrease, which can explain the trend in Figure 16a.

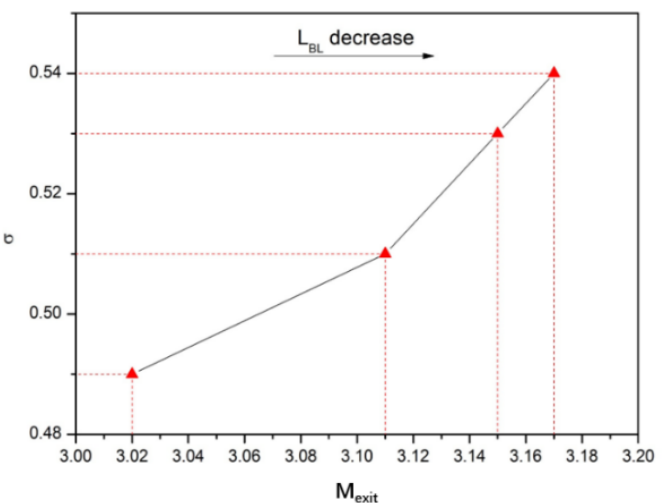

(a)

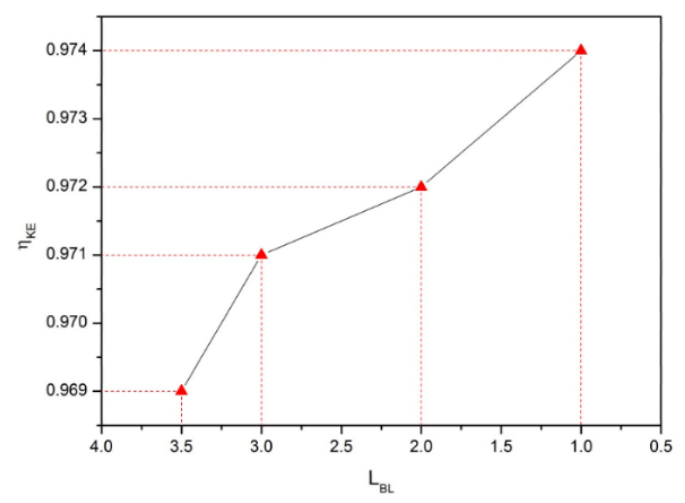

(c)

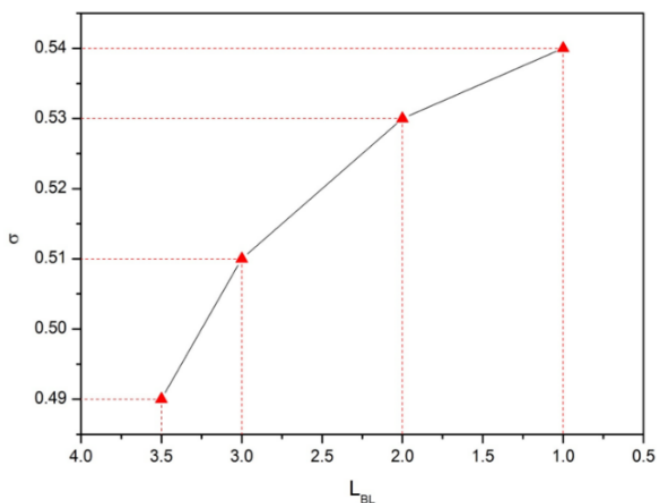

(b)

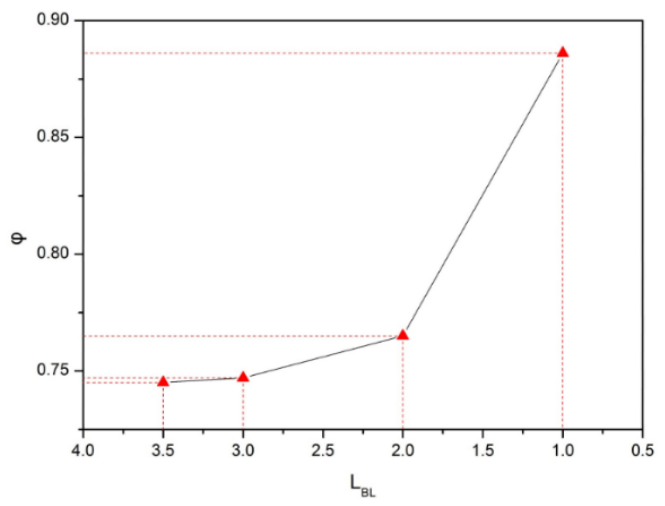

(d)

Figure 16. Aerodynamic characteristics of inlet exit under different boundary layer thicknesses (unit of $L_{\mathrm{BL}}: \mathrm{m}$ ). (a) $\sigma-M_{\text {exit }}$ distribution; (b) $\sigma-L_{\mathrm{BL}}$ distribution; (c) $\eta_{\mathrm{KE}}-L_{\mathrm{BL}}$ distribution; (d) $\varphi-L_{\mathrm{BL}}$ distribution.

According to Figure $16 c, d, \sigma$ and $\eta_{\mathrm{KE}}$ increase to a certain extent. When $L_{\mathrm{BL}}$ decreases from 3.5 to $2.0 \mathrm{~m}$, the mass capturing ratio $\varphi$ only increases by $2.6 \%$, while it increases by $13.7 \%$ when $L_{\mathrm{BL}}$ decreases from 2.0 to $1.0 \mathrm{~m}$. This notion indicates that the incident shock is distorted by the disturbance of the boundary layer at $L_{\mathrm{BL}}>2.0 \mathrm{~m}$. Meanwhile, the disturbance at $L_{\mathrm{BL}}<2.0 \mathrm{~m}$ is not strong enough to induce shock distortion. The $\eta_{\mathrm{KE}}$ is positively related to the $L_{\mathrm{BL}}$. According to the definition of $\eta_{\mathrm{KE}}$ (Equation (3)), a highly nonlinear relationship exists between $\eta_{\mathrm{KE}}$ and $L_{\mathrm{BL}}$. A clear trend in the $\eta_{\mathrm{KE}}-L_{\mathrm{BL}}$ distribution is difficult to obtain. The $\eta_{\mathrm{KE}}-R_{\mathrm{M}}$ distribution is presented in the following analysis to evaluate the overall compressing efficiency of inlet. The inlet efficiency is shown in Figure 17. The hypersonic inlet expert Van Wie [38] proposed to use the kinetic efficiency $\eta_{\mathrm{KE}}$ for the inlet performance evaluation. The definition of $\eta_{\mathrm{KE}}$ is shown in Equation (3). This expression includes the kinetic energy of the inlet exit and the transferred internal energy caused by the flow expansion. The $\eta_{\mathrm{KE}}-R_{\mathrm{M}}$ distribution is used to show the inlet 
efficiency. Van wie [38-41] proposed the $\eta_{K E}-R_{M}$ relation below, which is based on $2 \mathrm{D}$ inlet experiments.

$$
\eta_{\mathrm{KE}}(1)=1-0.4\left(1-R_{\mathrm{M}}\right)^{4}
$$

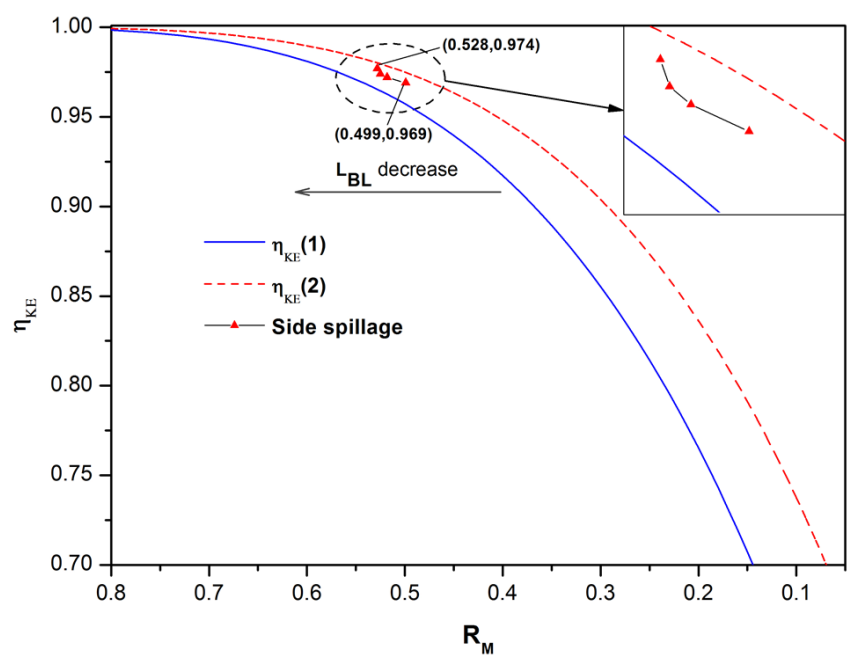

Figure 17. Inlet efficiency based on different boundary layer thicknesses.

Kouichiro [42] proposed another $\eta_{\mathrm{KE}}-R_{\mathrm{M}}$ relation, which is based on side-compression inlet experiments. The relation is shown as follows:

$$
\eta_{\mathrm{KE}}(2)=1-0.528\left(1-R_{M}\right)^{3.63},
$$

This work uses the above two relations as the standards to evaluate inlet efficiency. In Figure 17, the solid blue line stands for the $\eta_{\mathrm{KE}}(1)$ relation, and the red dashed line indicates the $\eta_{\mathrm{KE}}(2)$ relation. The higher inlet efficiency locates at the upper-right side of the figure. The lower inlet efficiency locates at the lower-left side of the figure. When the $L_{\mathrm{BL}}$ decreases from 3.5 to $2.0 \mathrm{~m}$, the $\eta_{\mathrm{KE}}-R_{\mathrm{M}}$ distribution is almost parallel to the $\eta_{\mathrm{KE}}(1)$ and $\eta_{\mathrm{KE}}(2)$ curves, which indicates that the inlet efficiency remains steady in this $L_{\mathrm{BL}}$ range. When the $L_{\mathrm{BL}}$ decreases from 2.0 to $1.0 \mathrm{~m}$, the $\eta_{\mathrm{KE}}-R_{\mathrm{M}}$ distribution approaches the $\eta_{\mathrm{KE}}(2)$ curve. This notion indicates that the inlet efficiency starts to increase in this $L_{\mathrm{BL}}$ range.

\section{Conclusions}

A novel side-spillage pattern for hypersonic bump inlet integration was proposed in this work to improve the start-ability at low-speed conditions. The conclusions are presented as follows.

The side-embedded shock effects were analyzed and a modular assessment was employed. It proved that the side-spillage pattern holds better flow spillage potentials than the typical central spillage pattern. The novel spillage-adaptive integration pattern was proposed based on the above analysis. Two side-located inlets are set back-to-back on a bump surface. The compression centers of inlets are located at two sides over the bump. The inlet presetting region is determined by four parameters: the bump configuration, the bump shock profile, the low-kinetic-energy (LKE) flow ratio, and the lateral flow deflection.

The numerical results show that the new bump inlet has similar aerodynamic characteristics to the typical central spillage bump inlet. The speed range (starting at $M$ 2.5-6.0) of the inlet is significantly wider than the typical integration pattern (starting at M 5.0-6.0). The relationship between the spillage ratio and the inflow speed is quasi-parabolic. The spillage ability increases with the decrease of the inflow speed.

The aerodynamic characteristics of inlets under various boundary layer ratios are obtained. The total pressure recovery $(\sigma)$ and mass capturing ratio $(\varphi)$ are sensitive to the thick boundary layer. When $L_{\mathrm{BL}}>2.0 \mathrm{~m}$, the $\sigma$ is rapidly increased with the decrease in $L_{\mathrm{BL}}$ 
while at $L_{\mathrm{BL}}<2.0 \mathrm{~m}$, the $\varphi$ is rapidly increased with the decrease in $L_{\mathrm{BL}}$. The analysis on the inlet efficiency indicated that the performance of the new spillage-adaptive bump inlet (results with thick boundary layer) is close to that of the side compression inlet (results without LKE inflow).

Author Contributions: Conceptualization, Z.Y. and G.H.; software, G.H.; validation, Z.Y., R.W. and O.M.; writing—original draft preparation, Z.Y.; writing—-review and editing, Z.Y., R.W. and O.M.; funding acquisition, Z.Y. and G.H. All authors have read and agreed to the published version of the manuscript.

Funding: This research was funded by National Natural Science Foundation of China (12002162), Natural Science Foundation of Jiangsu Province (BK20200449), National Science and Technology Major Project (J2019-II-0007-0027), Graduate Research and Practice Innovation Program of Nanjing University of Aeronautics and Astronautics (xcxjh20210203), Jiangsu Postdoctoral Research Foundation (2021K307C). The APC was funded by Natural Science Foundation of Jiangsu Province (BK20200449).

Data Availability Statement: Not applicable.

Acknowledgments: The authors are grateful for the help from Wenyou Qiao in the preliminary bump inlet design concept subjected to the non-uniform inflow (i.e., the central-spillage integrated form).

Conflicts of Interest: The authors declare no conflict of interest.

\section{References}

1. Ding, F.; Liu, J.; Shen, C.B.; Huang, W. Novel inlet-airframe integration methodology for hypersonic waverider vehicles. Acta. Astronaut. 2015, 111, 178-197. [CrossRef]

2. Shi, L.; Yang, Y.; Zhao, G.; Liu, P.; He, G. Research and development on inlets for rocket based combined cycle engines. Prog. Aerosp. Sci. 2020, 117, 100639. [CrossRef]

3. Sziroczak, D.; Smith, H. A review of design issues specific to hypersonic flight vehicles. Prog. Aerosp. Sci. 2016, 84, 1-28. [CrossRef]

4. Can, A.; Ashish, A.S.; Apostolos, P. Conceptual Advanced Transport Aircraft Design Configuration for Sustained Hypersonic Flight. Aerospace 2018, 5, 5030091.

5. Yu, Z.; Huang, G.; Xia, C. Inverse design and Mach 6 experimental investigation of a pressure controllable bump. Aerosp. Sci. Technol. 2018, 81, 204-212. [CrossRef]

6. Brahmachary, S.; Fujio, C.; Ogawa, H. Multi-point design optimization of a high-performance intake for scramjet-powered ascent flight. Aerosp. Sci. Technol. 2020, 107, 106362. [CrossRef]

7. Yu, C.; Jiang, J.; Zhen, Z.; Bhatia, A.K.; Wang, S. Adaptive backstepping control for air-breathing hypersonic vehicle subject to mismatched uncertainties. Aerosp. Sci. Technol. 2020, 107, 106244. [CrossRef]

8. Zhang, D.; Tang, S.; Cao, L.; Cheng, F.; Deng, F. Research on control-oriented coupling modeling for air-breathing hypersonic propulsion systems. Aerosp. Sci. Technol. 2019, 84, 143-157. [CrossRef]

9. Shi, W.; Chang, J.; Wang, Y.; Bao, W.; Liu, X. Buzz evolution process investigation of a two-ramp inlet with translating cowl. Aerosp. Sci. Technol. 2019, 84, 712-723. [CrossRef]

10. Shi, W.; Chang, J.; Zhang, J.; Ma, J.; Wang, Z.; Bao, W. Numerical investigation on the forced oscillation of shock train in hypersonic inlet with translating cowl. Aerosp. Sci. Technol. 2019, 87, 311-322. [CrossRef]

11. Ma, K.; Zhang, Z.; Liu, Y.; Jiang, Z. Aerodynamic principles of shock-induced combustion ramjet engines. Aerosp. Sci. Technol. 2020, 103, 105901. [CrossRef]

12. Kantrowitz, A.; Donaldson, C.D. Preliminary Investigation of Supersonic Diffusers. NACA 1945, 1945, WRL-713.

13. Xie, W.Z.; Yang, W.; Jin, Y.; Yang, S.; Guo, S. Prediction of self-starting limit of two-dimensional supersonic inlets considering viscous effects. Aerosp. Sci. Technol. 2020, 106, 106229. [CrossRef]

14. Xie, W.; Jin, Y.; Ge, Y.; Yang, S.; Zeng, C.; Guo, S. Feasibility of employing the restarting process to evaluate the self-starting ability for hypersonic inlets. Aerosp. Sci. Technol. 2020, 107, 106347. [CrossRef]

15. Wang, C.; Yang, X.; Xue, L.; Kontis, K.; Jiao, Y. Correlation Analysis of Separation Shock Oscillation and Wall Pressure Fluctuation in Unstarted Hypersonic Inlet Flow. Aerospace 2019, 6, 8. [CrossRef]

16. Yu, Z.; Huang, G.; Xia, C.; Huihui, H. An Improved Internal-Waverider-Inlet with High External-Compression for Ramjet Engine. In Proceedings of the 20th AIAA International Space Planes and Hypersonic Systems and Technologies Conference, Glasgow, UK, 6-9 July 2015.

17. Xiong, B.; Fan, X.Q.; Wang, Y. Parameterization and optimization design of a hypersonic inward turning inlet. Acta Astronaut. 2019, 164, 130-141. [CrossRef] 
18. Chen, S.; Liu, J.; Ding, F.; Huang, W. Novel design methodology of integrated waverider with drip-like intake based on planform leading-edge definition method. Acta Astronaut. 2020, 167, 314-330. [CrossRef]

19. Ding, F.; Liu, J.; Shen, C.B.; Huang, W. Novel approach for design of a waverider vehicle generated from axisymmetric supersonic flows past a pointed von Karman ogive. Aerosp. Sci. Technol. 2015, 42, 297-308. [CrossRef]

20. Qiao, W.; Anyuan, Y.U.; Gao, W.; Wang, W. Design method with controllable velocity direction at throat for inward-turning inlets. Chin. J. Aeronaut. 2019, 32, 1403-1415. [CrossRef]

21. Qiao, W.; Yu, A.; Yang, D.; Le, J. Integration design of inward-turning inlets based on forebody shock wave. Acta Aeronaut. Astronaut. Sin. 2018, 39, 60-71.

22. Zhou, H.; Jin, Z. A novel approach for inverse design of three-dimensional shock waves under non-uniform flows. Acta Astronaut. 2020, 176, 324-331. [CrossRef]

23. Zhou, H.; Jin, Z.; Ge, N. Design method for non-axisymmetric generalized internal conical flowfield based on double 3D curved shock waves. Aerosp. Sci. Technol. 2020, 105, 105971. [CrossRef]

24. Youssefi, M.R.; Knight, D. Assessment of CFD Capability for Hypersonic Shock Wave Laminar Boundary Layer Interactions. Aerospace 2017, 4, 4020025.

25. Running, C.L.; Juliano, T.J. Global Skewness and Coherence for Hypersonic Shock-Wave/Boundary-Layer Interactions with Pressure-Sensitive Paint. Aerospace 2021, 8, 123. [CrossRef]

26. Ferrero, A. Control of a Supersonic Inlet in Off-Design Conditions with Plasma Actuators and Bleed. Aerospace 2020, 7, 32. [CrossRef]

27. Häberle, J.; Gülhan, A. Internal Flowfield Investigation of a Hypersonic Inlet at Mach 6 with Bleed. J. Propuls. Power 2007, 23, 1007-1017. [CrossRef]

28. Goldfeld, M.A. Influence of flow conditions on compression surfaces of hypersonic inlet on characteristics of boundary layer bleed. J. Phys. Conf. Ser. 2019, 1382, 012076. [CrossRef]

29. Liu, J.; Fan, X.; Tao, Y.; Liu, W. Experimental and numerical study on the local unstart mechanism of hypersonic inlet. Acta Astronaut. 2019, 160, 216-221. [CrossRef]

30. Cakir, B.O.; Saracoglu, B.H. Numerical Assessment of Ramjet Intake Flow Topology Optimization for Off-Design Operation via Bypass Boundary Layer Bleed. AIAA Propuls. Energy 2020 Forum. 2020. [CrossRef]

31. Wang, Y.; Yang, S.; Zhang, D.; Deng, X. Design of Waverider Configuration with High Lift-Drag Ratio. J. Aircr. 2007, 44, 144-148.

32. Huang, G.; Zuo, F.; Qiao, W. Design method of internal waverider inlet under non-uniform upstream for inlet/forebody integration. Aerosp. Sci. Technol. 2018, 74, 160-172. [CrossRef]

33. Guoping, H.; Zonghan, Y.; Chen, X. 3D inverse method of characteristics for hypersonic bump-inlet integration. Acta Astronaut. 2020, 166, 11-22.

34. Yu, Z.; Huang, G.; Xia, C.; Sesterhenn, J. A pressure-controllable bump based on the pressure-ridge concept. Aerosp. Sci. Technol. 2019, 87, 133-140. [CrossRef]

35. Zhang, J.; Yuan, H.; Wang, Y.; Huang, G. Experiment and numerical investigation of flow control on a supersonic inlet diffuser. Aerosp. Sci. Technol. 2020, 106, 106182. [CrossRef]

36. Lisen, Q. Solution of Shock with Variable Specific Heat for Calculation of Hypersonic Inlet. J. Aerosp. Power 2020, 15, 105-108.

37. Liang, D.; You, Y.; Guo, R. High Enthalpy Wind Tunnel Tests of Three-Dimensional Section Controllable Internal Waverider Hypersonic Inlet. In Proceedings of the AIAA Aerospace Sciences Meeting Including the New Horizons Forum and Aerospace Exposition, Orlando, FL, USA, 5-8 January 2009.

38. Van Wie, D. Scramjet inlets. Scramjet Propuls. 2000, 189, 447-511.

39. Ault, D.A.; van Wie, D.M. Experimental and computational results for the external flowfield of a scramjet inlet. J. Propuls. Power 1994, 10, 533-539. [CrossRef]

40. van Wie, D. Techniques for the measurement of scramjet inlet performance at hypersonic speeds. In Proceedings of the AlAA 4th International Aerospace Planes Conference, Orlando, FL, USA, 4 December 1992.

41. van Wie, D.M.; Ault, D.A. Internal flowfield characteristics of a scramjet inlet at Mach 10. J. Propuls. Power 1996, 12, 158-164. [CrossRef]

42. Tai, K.; Kanda, T.; Kudou, K.; Murakami, A.; Komuro, T.; Itoh, K. Aerodynamic performance of scramjet inlet models with a single strut. In Proceedings of the 31st Aerospace Sciences Meeting, Reno, NV, USA, 11-14 January 1993. 